\title{
Wind-solar generator
}

\author{
Lev Efimovich Kopelevich \\ Department of Electrical Engineering and Electrical \\ Machines \\ Kuban State Technological University \\ Krasnodar, Russia \\ kkllev@mail.ru \\ Aleksandr Yakovlevich Kashin \\ Department of Electrical Engineering and Electrical \\ Machines \\ Kuban State Technological University \\ Krasnodar, Russia \\ jlms_1@mail.ru
}

\author{
Bogaudin Khamidovich Gaitov \\ Department of Electrical Engineering and Electrical \\ Machines \\ Kuban State Technological University \\ Krasnodar, Russia \\ kkllev1@mail.ru
}

\author{
Mikhail Sergeyevich Khristoforov \\ Department of Electrical Engineering and Electrical \\ Machines \\ Kuban State Technological University \\ Krasnodar, Russia \\ khristoforov87@mail.ru
}

\author{
Polina Vitalievna Sereda \\ Department of Technical and Scientific Translation \\ Kuban State Technological University \\ Krasnodar, Russia \\ polinapost@list.ru
}

\begin{abstract}
The article considers a wind-solar generator based on special electric machines for power supply of various objects. The subject of this article is a wind-solar generator intended for simultaneous conversion of solar energy (using a photoelectric converter) and wind into electrical energy according to end-user performance $(U=380 \mathrm{~V}, f=50 \mathrm{~Hz})$. This work was carried out within the research conducted at Kuban State Technological University in the field of renewable energy sources under the guidance of professor B. Gaitov, the Honored worker of science and technology of the Russian Federation. The purpose of this work is to study the transient processes of a wind-solar generator. The results of this work is the mathematical model created in the "Matlab" software that allows one to take into account the electromechanical and electromagnetic processes, which take place in the wind-solar generator. The authors also formed oscillograms of the transient processes of the output voltage of the wind-solar generator when the input quantities change).
\end{abstract}

\section{Keywords - wind-solar generator, transient processes.}

\section{INTRODUCTION}

The existence of humankind depends on the energy that people receive from various sources. The energy that we use today is mainly derived from fossil fuels. Coal, oil and natural gas are fossil fuels that are considered to be not renewable, as their resources may be depleted in the near future. In addition, the burning of fossil fuels leads to pollution and other negative impacts on the natural environment. Unlimited sources of energy are renewable energy sources (for example, sun and wind energy). Rather often, newly developed oil and gas fields are located at a sufficient distance from the centralized energy supply. It seems advisable for such objects to use alternative energy (as one of the energy types).

Nowadays, in the field of alternative energy, which is based on the use of renewable energy sources, the problem of simultaneous use of several renewable energy sources (for example wind and sun energy) is being solved in different ways. Combination of energy from several renewable energy sources in one installation is more energy efficient than combination of energy from several installations, each of which receives energy from one of the renewable energy sources. Therefore, it is relevant to create such devices, in particular, electric generators, in which the energy is combined from several renewable energy sources. Such machines must have several inputs, each of which has its own energy source. Due to the widespread availability of solar and wind energies, it is advisable to create two-input electric machines (EM), i.e. machines that have two inputs from two different energy sources, for example electrical energy produced by photoelectric converters under the influence of solar radiation, and mechanical energy produced by wind installations $[1,2]$.

The studies of alternative energy are mainly aimed at improving the use of electromechanical energy converters during the conversion of one type of RES [3-13].

The development, design and research of special electric machines are considered in the literature without taking into account the features of the equipment for wind-solar energy 
[14-17]; that is, without taking into account permanent changes in the input parameters of EM. Thus, the agenda is the development of an electromechanical energy converter for use in the "wind + sun = electric energy" systems.

\section{RESULTS AND DISCUSSION}

Works related to RES are being carried out in Federal State Budgetary Educational Institution of Higher Education "Kuban State Technological University" for a number of years.

Fig. 1 shows the scheme of the classical electrotechnical wind-solar complex, Fig. 2 shows an electrotechnical windsolar complex based on a two-input electric machine (TEM)

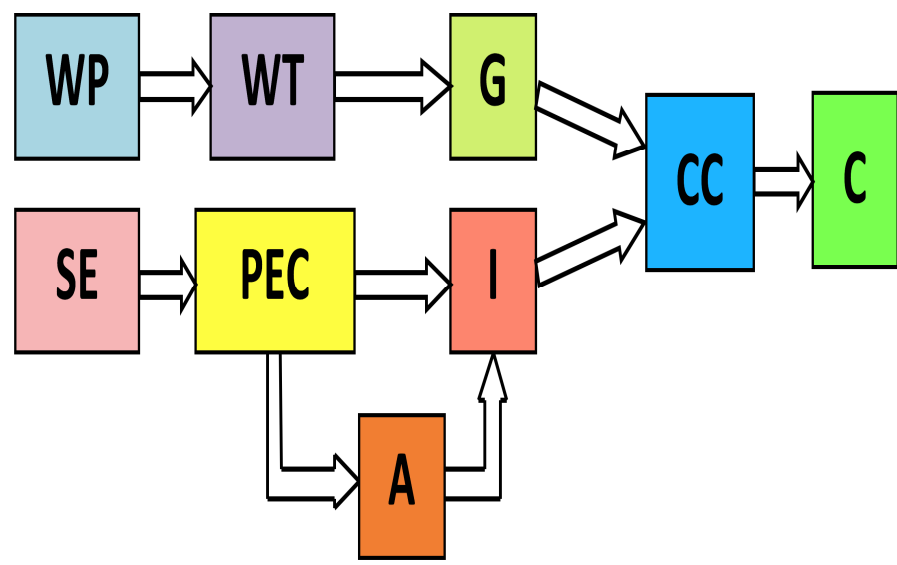

Fig. 1. Scheme of classical power plant based on photoelectric converter (PEC) and rotary transformer WP - wind power; SE - sun energy; WT - wind turbine; G - generator; PEC - photoelectric converter; A - accumulator; I inverter; $\mathrm{CC}$ - combiner-controller; $\mathrm{C}$ - consumer.

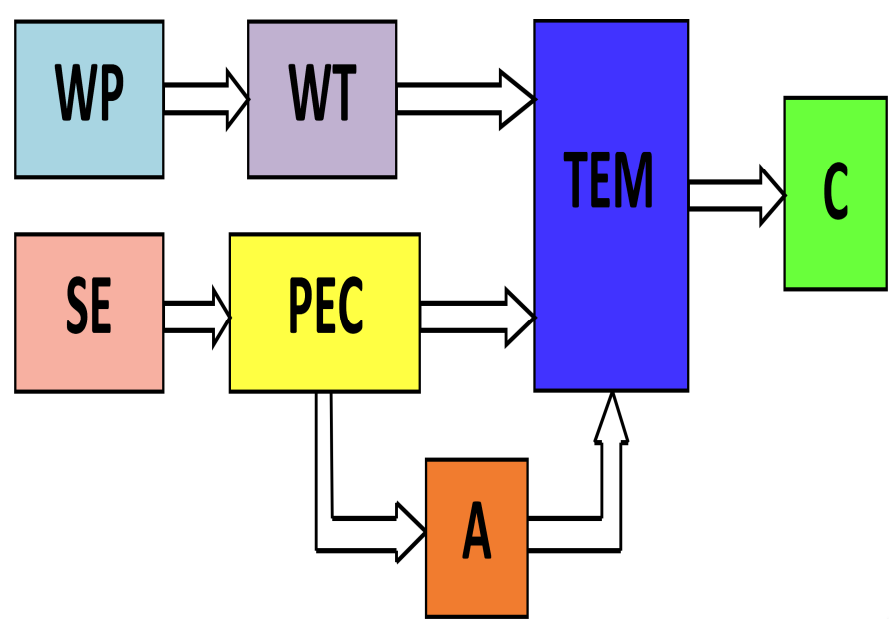

Fig. 2. Schematic diagram of power plant based on PEC and rotary transformer WP using TEM WP - wind power; SE - sun energy; WT - wind turbine; FEC - photoelectric converter; A - accumulator; TEM is a two-input electric machine; $\mathrm{C}$ - consumer

The wind-solar generator is an electromechanical device that combines in its case two nine-phase synchronous alternators, two nine-phase rectifiers and a three-phase synchronous alternator. Nine-phase synchronous generators are needed to reduce the ripple factor. The peculiarity of this machine is the possibility of efficient use of two renewable energy sources (RES). For example, as a converter of mechanical energy of rotation (wind power) supplied to the mechanical input of the machine, and as electric energy of direct current (solar energy converted by photoelectric converters into electricity direct current).

Figure 3 shows the construction of the wind solar generator (WSG), Fig. 4 shows its electrical circuit (the design and diagram are presented without a wind turbine and solar panels).

WSG comprises (Fig. 3.): casing 1, multi-pole permanent magnet 2 of pilot exciter inductor, magnetic core 3 with armature winding 4 of pilot exciter armature, single-phase winding 5 of exciter feeding and additional winding 6 of exciter feeding. In addition it includes inner axial magnetic core 7 with multiphase winding 8 of exciter armature and onephase feeding winding 9 of the main generator, axial magnetic core 10 with multiphase winding 11 of the main generator armature. There is also shaft 12 mounted in bearing units 13 and 14 and rigidly connected to permanent multi-pole magnet 2 of pilot exciter inductor via disc 15 and to internal axial yoke 7 via disc 16, nine-phase rectifiers 17 and 18, contacts 19 for connecting an external DC power supply (e.g., solar battery) to additional exciter feeding 6 . Single-phase winding 5 of exciter feeding is connected to the multiphase winding 4 of pilot exciter armature via multi-phase rectifier 17 . The onephase excitation winding 9 of the main generator is connected to the multiphase winding 8 of the armature through the multiphase rectifier 18 . From a three-phase winding 11 of the main generator armature, a three-phase electromotive force can be fed into the network.

WSG works in the following way: when the shaft 12 is rotated by an external mechanism (for example, by a wind turbine), a permanent multi-pole magnet 2 of the exciter inductor and a magnetic circuit 7 with windings 8, 9 and a rectifier 18 are rotated together with the shaft 12 . The magnetic flux produced by the permanent multi-pole magnet 2 interacts with the multiphase winding 4 of the exciter armature, which is placed into the grooves of the magnetic yoke 3 on the side of the permanent multi-pole magnet 2, and induces in it a multiphase EMF system that is rectified by a nine-phase rectifier 17 and fed to a single-phase winding 5 of exciter feeding, which is placed into the grooves of the inner axial magnetic yoke 3 from the side of the magnetic yoke 7 . In this case, a magnetic flux is created in the single-phase winding 5 of exciter feeding.

The magnetic flux generated by a single-phase winding 5 of exciter feeding is added to the direction according to the magnetic flux generated by the additional winding 6 (current flow through the coil 6 is provided on the feeding coil through contacts 19 of DC voltage, e.g., from solar cells). According to the superposition principle of the magnetic fields, the magnetic fluxes, which were generated by the windings 5 and 6 are summed. The resulting magnetic flux induces a rotating winding 8 of exciter armature, which is placed into the grooves of the axial magnetic yoke 7 from the side of the axial 
magnetic yoke 3, a multiphase EMF system which is rectified by multiphase (in Figure 4 -. by a nine-phase) rectifier 18 and fed to a single-phase winding 9 of the main generator, placed into the grooves of axial yoke 7 from the side of axial yoke 10 . In this case, a one-phase winding 9 of the main generator feeding creates a magnetic flux which induces a three-phase EMF for supply to the network in winding 11 of the main generator armature.

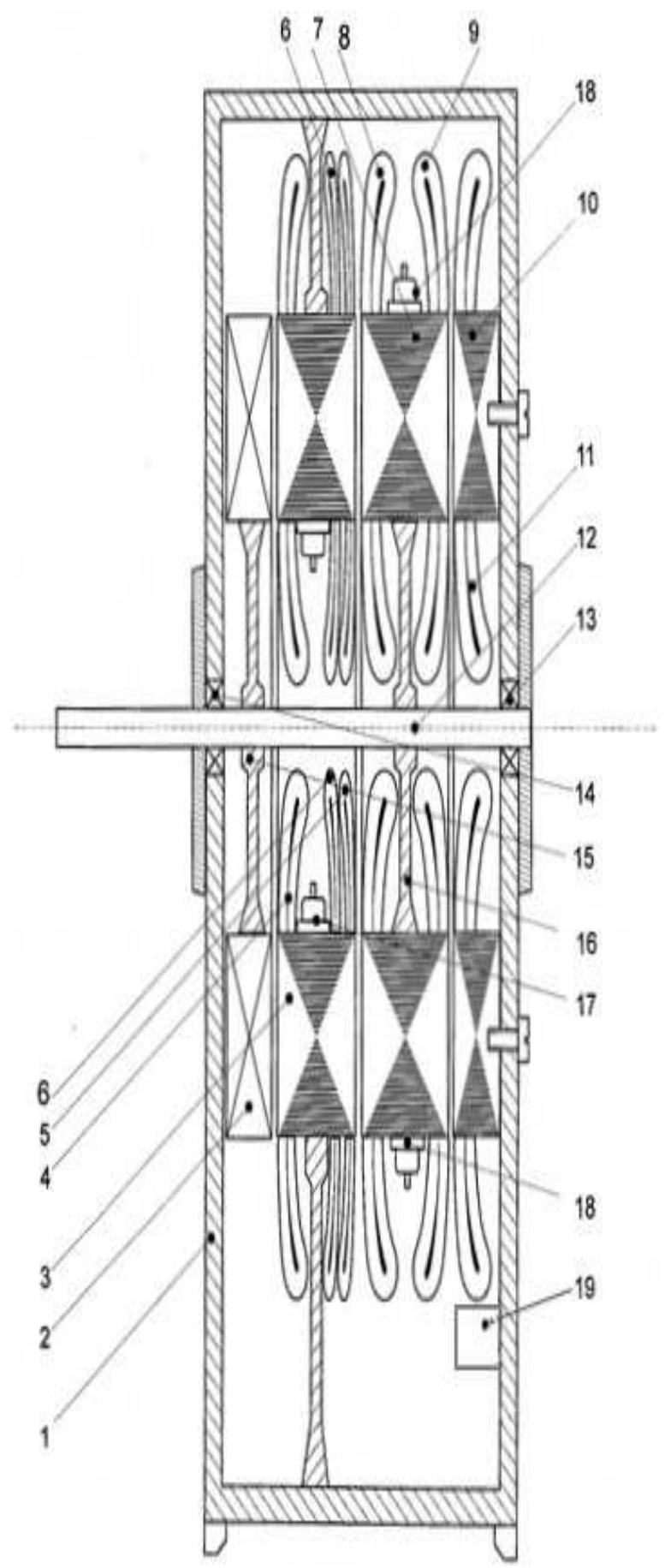

Fig. 3. Wind-solar generator

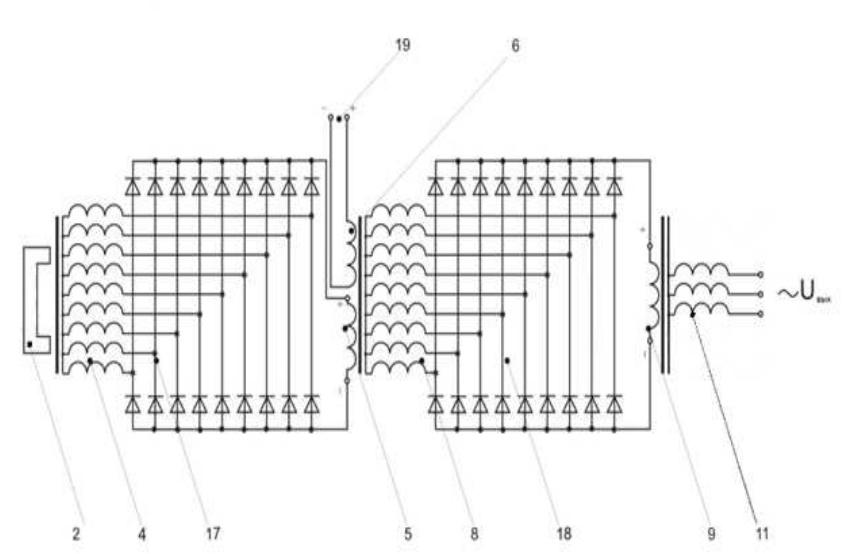

Fig. 4. Electrical diagram of wind-solar generator

Application of two similar systems (9-phase winding - 9phase bridge rectifier - DC winding) allows one to reduce pulsations in the machine.

In order to obtain a picture of WSG the transient processes, we created its model in the Matlab software [18], shown in Fig. 5, in Table. 1.

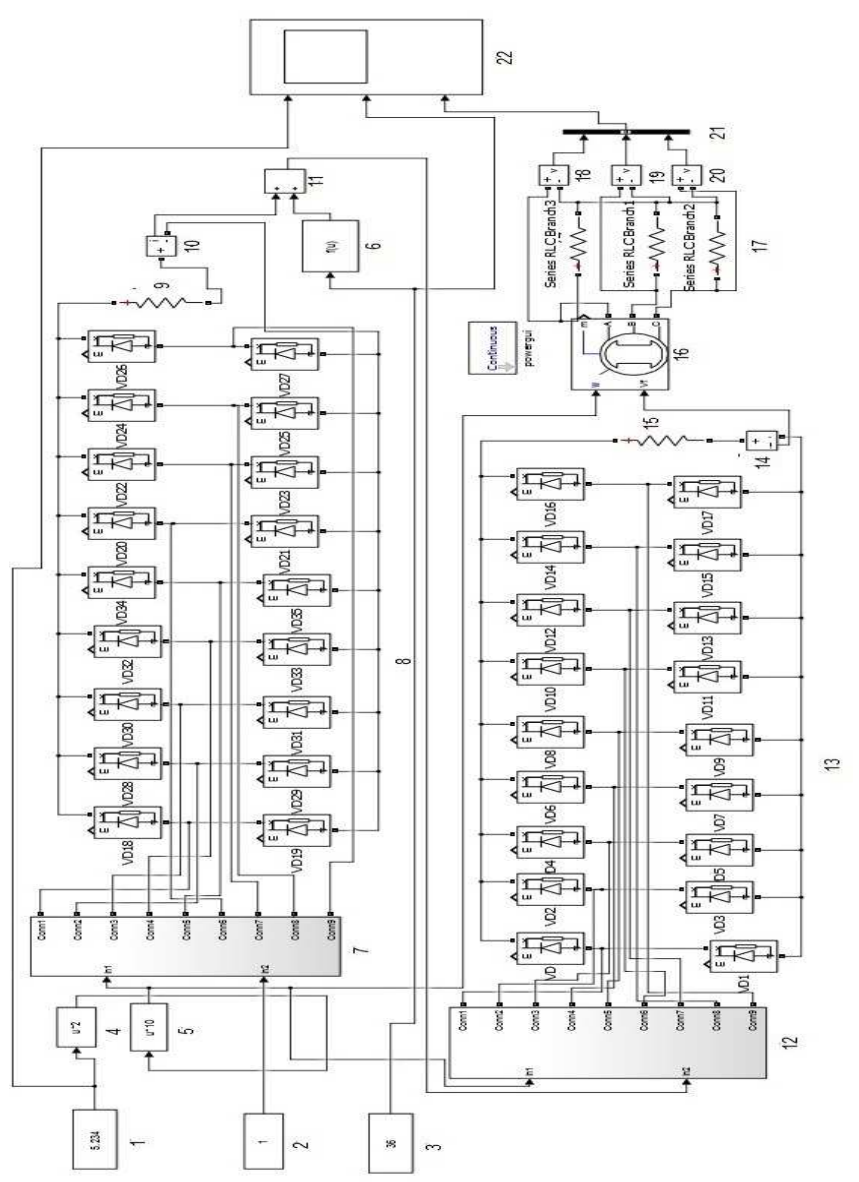

Fig. 5. Flowchart of WSG model 
TABLE I. BLOCKS' FUNCTIONS FROM THE FLOWCHART

\begin{tabular}{|c|c|c|}
\hline Block № & Block name & Block function \\
\hline 1 & Constant & $\begin{array}{l}\text { Designed for setting the speed } \\
\text { of air flow }\end{array}$ \\
\hline 2 & Constant & $\begin{array}{l}\text { Designed for setting the } \\
\text { excitation current }\end{array}$ \\
\hline 3 & Constant & $\begin{array}{l}\text { Designed to set the voltage of } \\
\text { the solar battery }\end{array}$ \\
\hline 4 & Fen & $\begin{array}{l}\text { Designed to simulate a wind } \\
\text { turbine }\end{array}$ \\
\hline 5 & Fen & $\begin{array}{l}\text { Designed to simulate the } \\
\text { multiplier }\end{array}$ \\
\hline 6 & Fen & $\begin{array}{l}\text { Designed to simulate a solar } \\
\text { battery }\end{array}$ \\
\hline 7,12 & $\begin{array}{l}\text { Model of a nine-phase } \\
\text { synchronous generator }\end{array}$ & Nine-phase generator \\
\hline 8,13 & $\begin{array}{l}\text { Model of a nine-phase } \\
\text { rectifier }\end{array}$ & $\begin{array}{l}\text { Designed for conversion of a } \\
\text { variable nine-phase current into } \\
\text { a constant pulsing current }\end{array}$ \\
\hline 11 & Add & $\begin{array}{l}\text { Designed for combination of } \\
\text { feeding signals }\end{array}$ \\
\hline 10,14 & Current Measurement & $\begin{array}{lll}\begin{array}{l}\text { Designed for } \\
\text { measurement }\end{array} & \text { current } \\
\end{array}$ \\
\hline 16 & $\begin{array}{l}\text { Synchronous Machine } \\
\text { SI Fundamental }\end{array}$ & $\begin{array}{l}\text { Three-phase synchronous } \\
\text { generator is designed for power } \\
\text { supply of objects }\end{array}$ \\
\hline 17 & Load block & Generator load \\
\hline 9,15 & Active Resistance & $\begin{array}{l}\text { Characterizes active resistance } \\
\text { of rectifiers }\end{array}$ \\
\hline $18,19,20$ & Voltage Measurement & $\begin{array}{lll}\begin{array}{l}\text { Designed for } \\
\text { measurement }\end{array} & \text { voltage } \\
\end{array}$ \\
\hline 21 & Bus creator & Executes the bus function \\
\hline 22 & Scope & $\begin{array}{l}\text { Performs the function of an } \\
\text { oscilloscope }\end{array}$ \\
\hline
\end{tabular}

The speed of the air flow is set in block 1; it is fed through blocks 4 and 5 to the mechanical input of a nine-phase synchronous generator (block 7). The signal from block 2 is fed to the electrical input of the unit 7. The output signal from block 7 goes to block 8, where the nine-phase alternating current is converted into a constant pulsating one. This rectified current is supplied to unit 11. This block is also supplied with a solar cell current from unit 6 , which receives solar cell voltages from unit 3 . Currents from blocks 8 and 6 are summed at block 11, and are fed to the electrical input of a nine-phase synchronous generator (block 12). A signal from block 5 is directed to the mechanical input. The output current from unit 12 is supplied to unit 13 , where the nine-phase alternating current is converted to a constant pulsating current. This current is fed to the electrical input of a three-phase synchronous machine (block 16). A signal is directed to the mechanical input from block 5. The output voltage is directed to unit 17. It is measured by units $18,19,20$ and fed to the oscilloscope via a bus.

The results of the presented work are the investigation of the transient processes of the wind-solar generator when power is supplied from the photoelectric converter and from the wind turbine.

Figures 6-15 show the characteristics obtained as a result of mathematical modeling.

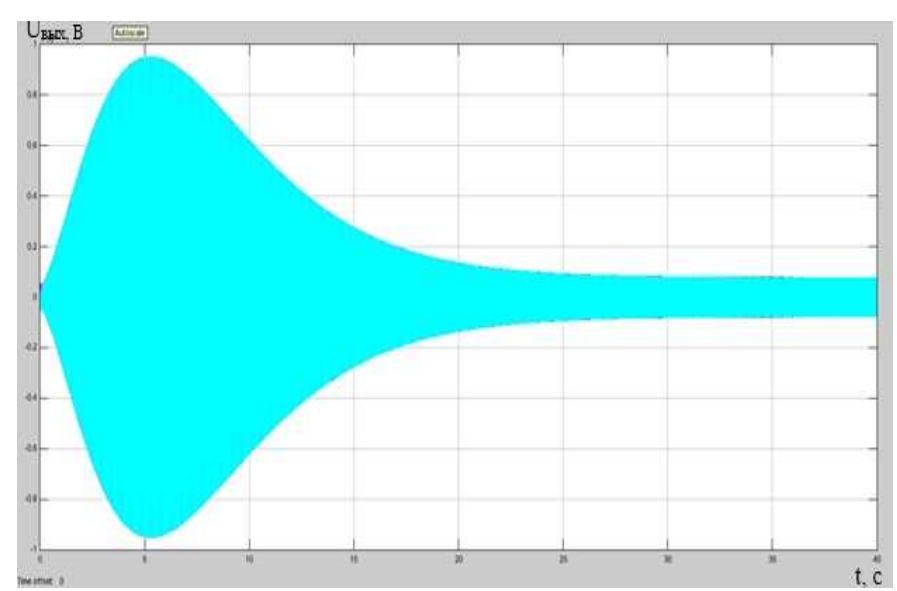

Fig. 6. Screenshot of the transient process oscillogram of the wind-solar generator

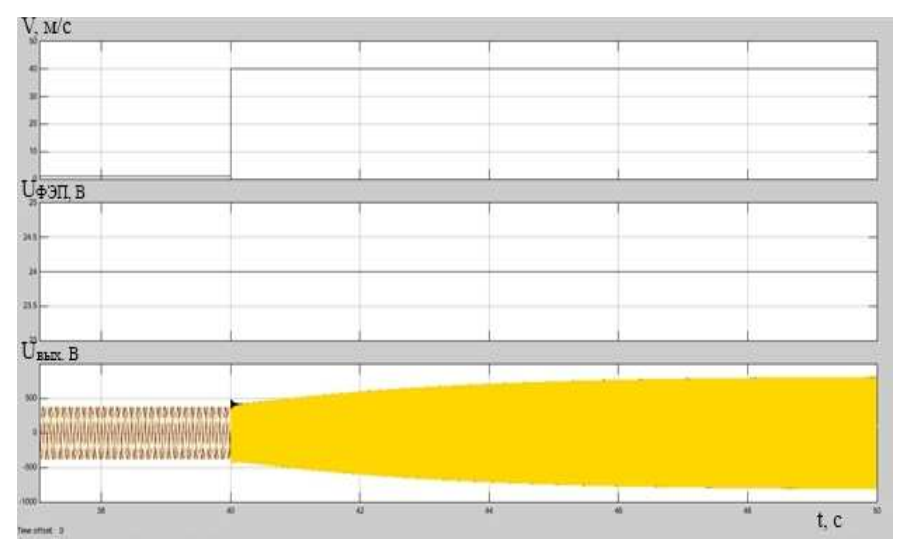

Fig. 7. A screenshot of the output voltage variation oscillogram with a change in the airflow velocity by a discontinuous jump

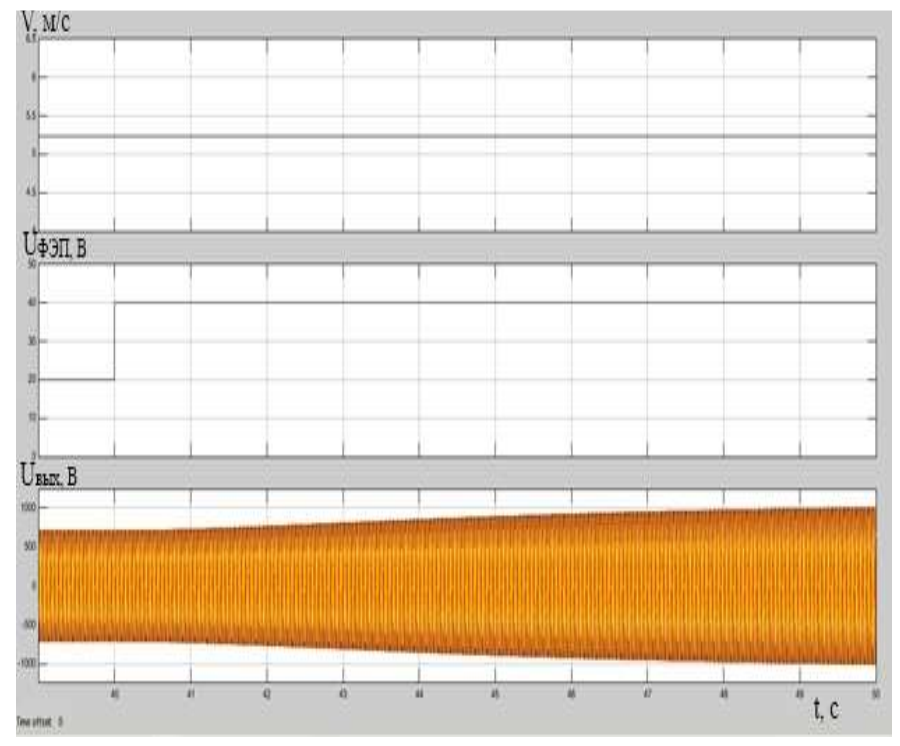

Fig. 8. Screenshot of the output voltage change oscillogram when the voltage of the solar battery changes abruptly 


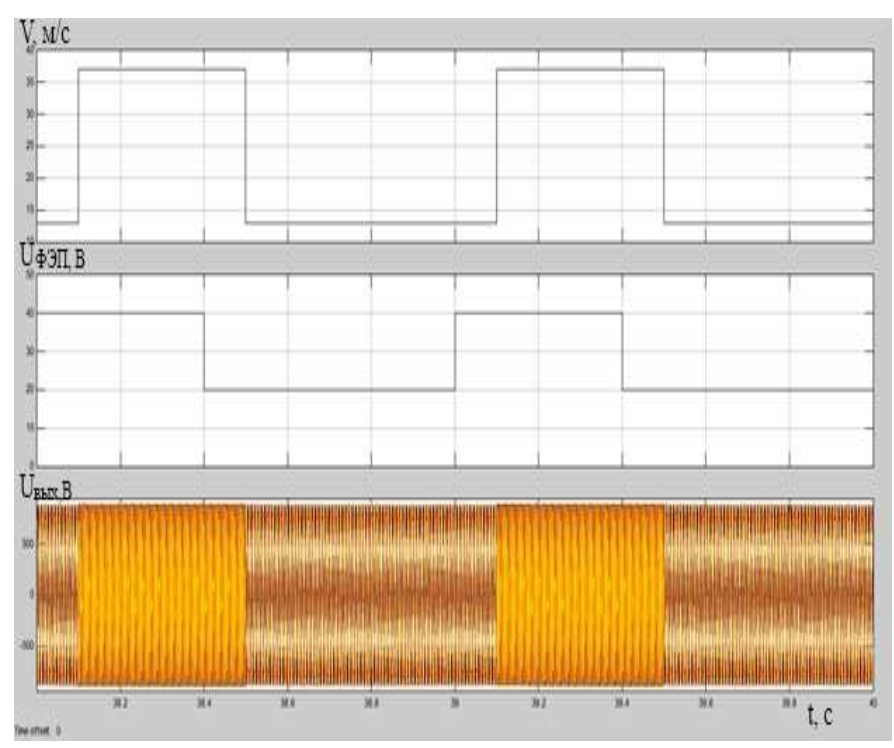

Fig. 9. A screenshot of the output voltage variation oscillogram with a change in the airflow rate and the voltage of the photoelectric converter by the meander

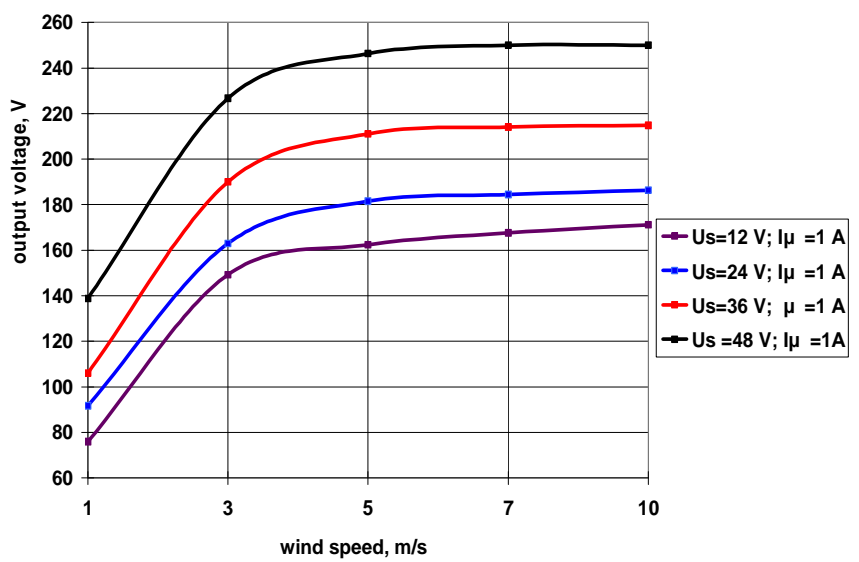

Fig. 10. Dependence graph for the effective value of the steady-state output WSG voltage on the wind speed

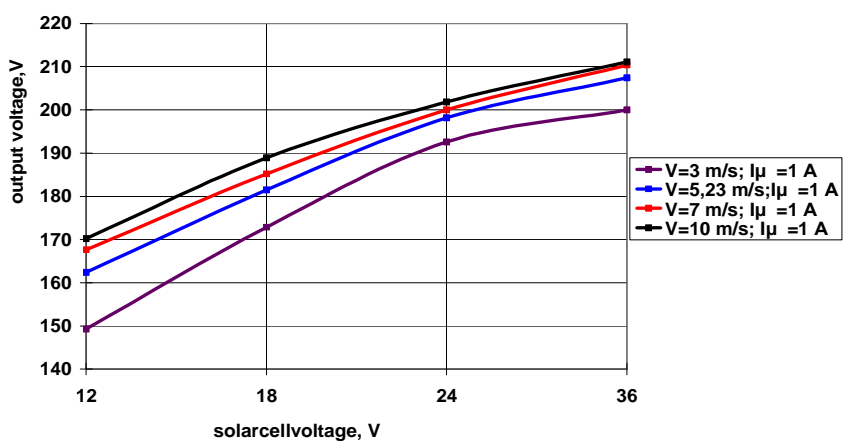

Fig. 11. Diagram for the effective value of the steady-state output WSG voltage on the voltage of the solar battery
The increase in wind speed above the value of $5.23 \mathrm{~m} / \mathrm{s}$ (Figure 10), which corresponds to the shaft speed of the machine - $1000 \mathrm{rpm}$, taken as the nominal value, with different values of the solar cell voltage, leads to an insignificant increase in the value of the output voltage. This is also explained by the saturation of the magnetic core 3 of WSG.

An increase in the current flowing through the additional winding 6 of exciter feeder (which corresponds to voltage increase at the output of solar cells) leads to an increase in the value of the WSG output voltage according to a nonlinear law (Fig. 11). Moreover, increasing the voltage of solar cells above $24 \mathrm{~V}$ does not lead to a more significant increase in the magnitude of the output voltage, which is explained by the saturation of the magnetic circuit 3 of WSG.

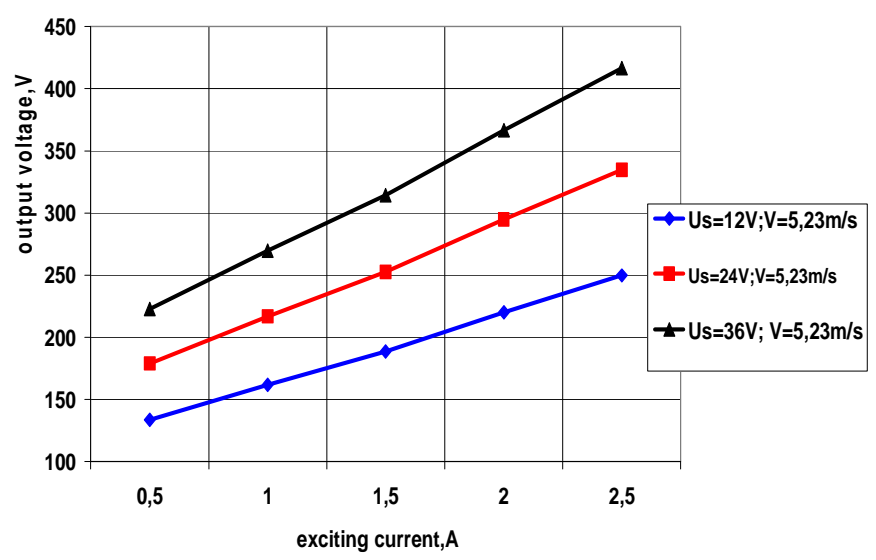

Fig. 12. Dependence graph for the effective value of the steady-state output WSG voltage on the magnetization parameters of the permanent magnet of the pilot exciter inductor

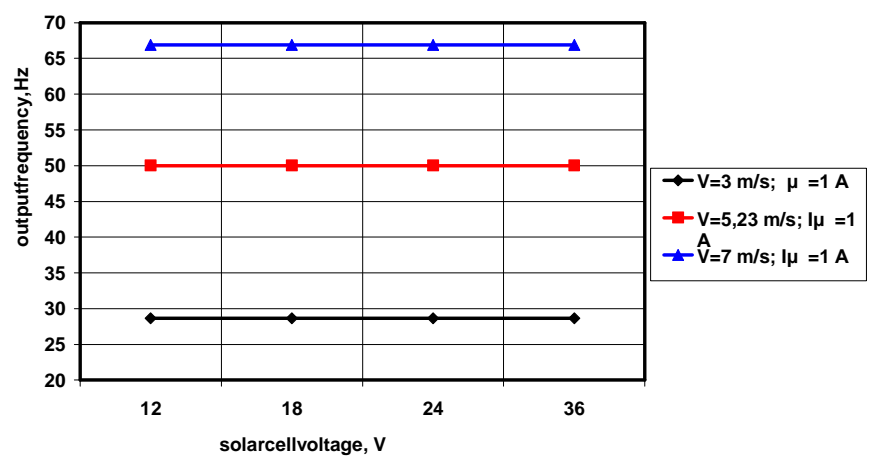

Fig. 13. Dependence graph for the output frequency of the output WSG voltage on the voltage of the solar battery 


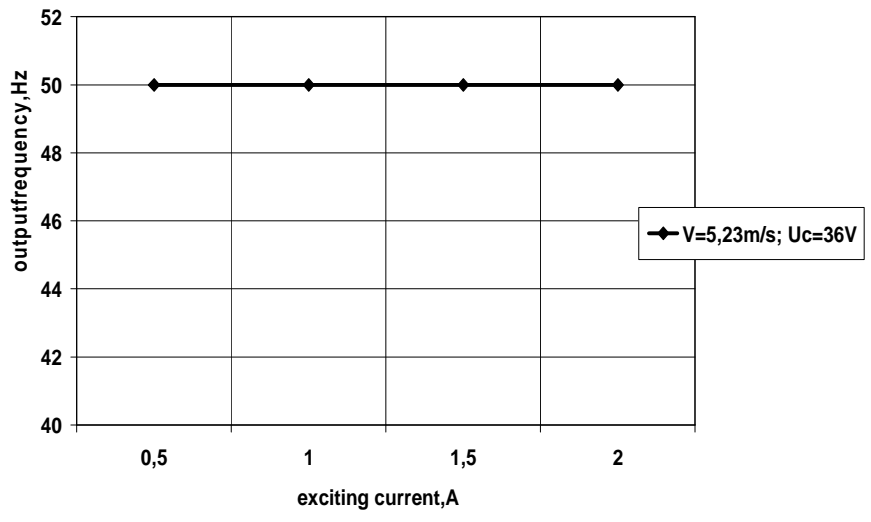

Fig. 14. Graph of dependence for the frequency of output WSG voltage on the magnetization of the permanent magnet of the pilot exciter inductor

Changes in the magnitude of the solar battery voltage (Figure 13) and the degree of magnetization of the multipolar magnet of the exciter inductor (Figure 14) do not affect the frequency of the WSG output voltage; it depends on rotation speed of the shaft 12 of the machine, which in turn depends on the wind speed.

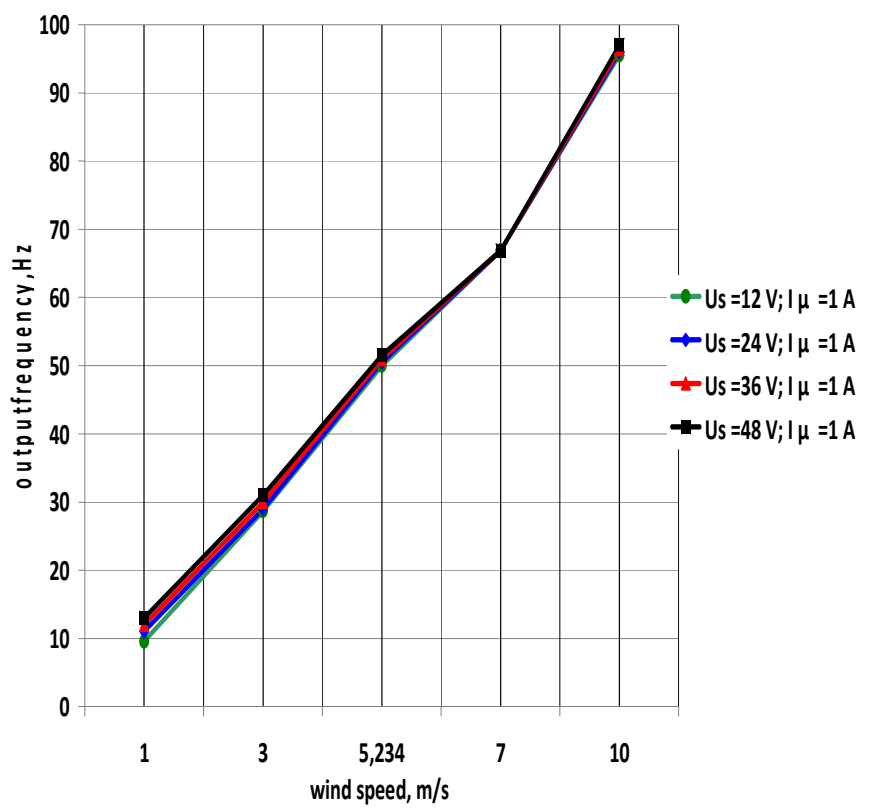

Fig. 15. Dependence graph for the output frequency of the output WSG voltage on the wind speed

\section{CONCLUSION}

As a result of the research, a mathematical model was created in the software "Matlab" that will help to study the wind-solar generator.
The study was carried out with the financial support of the Russian Foundation for Basic Research and the Administration of Krasnodar Region within the framework of scientific project No. 16-48-230500 a (p).

\section{References}

[1] EA. Zelenskaya, B.Kh. Gaitov, LE Kopelevich, AV Samorodov, Ya.M. Kashin, NV Ladenko "Wind-solar generators for power supply of oil and gas industry facilities," Gas industry, No. 6 (707), pp. 114-117, 2014.

[2] TB Gaytova, YaM. Kashin, LE Kopelevich, AYa. Kashin, AS. Knyazev, "Mathematical modeling of perspective generator sets for autonomous power supply systems," University news. Electromechanics, No. 3, pp.16-23, 2013.

[3] AK Sokolsky, Wind energy abroad and in Russia - current state and prospects, Sat. "Renewable energy sources", Moscow: MSU, 2005, pp.135-154.

[4] EK Soboleva, AV Sarazov, The use of wind and solar energy in the Volgograd region, Modern scientific research and innovations, № 5. Part 1, 2014ю Retrieved from: http://web.snauka.ru/issues/2014/05/34221web.snauka.ru/issues/2014/05 134221

[5] Kamjoo, A. Maheri, A.M. Dizqah, G.A. Putrus, "A.Multi-objective design under uncertainties of hybrid renewable energy system using NSGA-II and chance constrained programming." International Journal of Electrical Power and Energy Systems, 74, pp. 187-194, 2016.

[6] Hands,S.Performance analysis \& energy benefits of a desiccant based solar assisted trigeneration system in a building / S. Sethuvenkatraman, M. Peristy, D. Rowe, S. White, Renewable Energy, № 85, pp. 865-879, 2016.

[7] C. Shang, D. Srinivasan, T. Reindl, An improved particle swarm optimisation algorithm applied to battery sizing for stand-alone hybrid power systems," International Journal of Electrical Power and Energy Systems, №74, pp. 104-117, 2016.

[8] R. Aubrée, F. Auger, M. Macé, L. Loron "Design of an efficient small wind-energy conversion system with an adaptive sensorless MPPT strategy," Renewable Energy, 86, pp. 280-291, 2016.

[9] M. Chinchilla, S. Arnaltes, J.C. "Control of permanent-magnet generators applied to variable-speed wind-energy systems connected to the grid," Burgos, IEEE Transactions on Energy Conversion, 21 (1), pp. 130-135, 2006.

[10] M. Kheshti, X. Kang, G. Song, Z. Jiao, "Modeling and fault analysis of doubly fed induction generators for gansu wind farm application," Canadian Journal of Electrical and Computer Engineering, 38 (1), 7072632, pp. 52-64, 2015.

[11] X.A. Ran, S. Miao, Z. Jiang, H. Xu, "Framework for uncertainty quantification and economic dispatch model with wind-solar energy," International Journal of Electrical Power and Energy Systems, 73, pp. 23-33, 2015.

[12] M. Sharafi, T.Y. ElMekkawy, E.L. Bibeau, "Optimal design of hybrid renewable energy systems in buildings with low to high renewable energy ratio," RenewableEnergy, 83, pp. 1026-1042, 2015.

[13] PP. Bezrukih, "The state and prospects for the development of renewable energy," Elektrika, No. 9, pp. 3-10, 2008.

[14] V.A. Balagurov, Design of special electric machines, M: High School, 1982, p. 272.

[15] I.P. Kopylov, Design of electrical machines, textbook for universities, Moscow: Yurayt Publishing, 2011, p.767

[16] S.A. Gandja, A.S. Martyanov "Technique of engineering calculation of valve electric machines with axial magnetic flux, "Bulletin of the South Ural State University, volume 13, No. 2, 2013, pp. 85-87.

[17] Gandja S.A. "Optimal design of electric drives based on valve electric machines with axial clearance," Bulletin of the South Ural State University, № 34, pp. 68-72, 2009. 
[18] Demo version of MatLabm, Retrieved from: https://www.mathworks.com/programs/trials/trial_request.html (date of application:

17.06.2017). 